\title{
EMPODERAMENTO DO PODER JUDICIÁRIO NAS QUESTÕES AFETAS A SEGURIDADE SOCIAL: INCREMENTALISMO OU INTERPRETAÇÃO CONSTITUCIONAL EVOLUTIVA EM MATÉRIA PREVIDENCIÁRIA
}

\author{
Viviane Freitas Perdigao Lima* \\ Renata Caroline Pereira Reis Mendes**
}

RESUMO: O estudo parte do empoderamento do juiz nas inúmeras possibilidades interpretativas da Constituição, analisa política pública e precedentes do judiciário no direito à aposentadoria. O referencial teórico pauta-se em um Judiciário ao substituir políticas públicas do Poder Executivo e Legislativo (BAUM, 1987) na proteção dos riscos sociais o faz numa análise cautelosa da Constituição sem causar grandes rupturas (BARAK, 2002; ARAÚJO, 2017). Metodologicamente foca-se na dinâmica de proteção social, interpretação constitucional, Projeto Expedição da Cidadania, Resp n. ${ }^{\circ}$ 1.352.721-SP e Resp n. ${ }^{\circ}$ 1649636/MT. Verifica-se postura judicial incrementando a constituição ao primar a solidariedade social.

Palavras-chave: Empoderamento. Poder Judiciário. Estado Constitucional. Direito Previdenciário. Interpretação Constitucional.

\section{EMPOWERING THE JUDICIARY POWER IN THE ISSUES AFFECTED SOCIAL SECURITY: INCREMENTALISM OR CONSTITUTIONAL INTERPRETATION IN PREVIOUS MATTERS}

ABSTRACT: The study starts from the empowerment of the judge in the innumerable interpretative possibilities of the Constitution, analyzes public politics and precedents of the judiciary in the right to retirement. The theoretical framework is based on a Judiciary, replacing the public policies of the Executive and Legislative Power (BAUM, 1987) in the protection of social risks, which is done in a cautious analysis of the Constitution without causing major disruptions (BARAK, 2002; ARAÚJO, 2017). Methodologically focuses on the dynamics of social protection, constitutional interpretation, Citizenship Expedition Project, Resp. 1. 352.721 and Resp n. ${ }^{\circ}$. 1.649.636/MT. Judicial posture is increased by increasing the constitution by giving priority to social solidarity.

Keywords: Empowerment. Judicial power. Constitutional State. Social Security Right. Constitutional interpretation.

\footnotetext{
* Viviane Freitas Perdigão Lima. Mestra em Direito pelo programa Direito e Instituições do Sistema de Justiça da Universidade Federal do Maranhão (UFMA). Professora da Universidade Estadual do Maranhão. Advogada. http://lattes.cnpq.br/7955567083507463.

** Renata Caroline Pereira Reis Mendes. Mestra em Cultura e Sociedade pela Universidade Federal do Maranhão. Professora do Instituto Florence de Ensino Superior (IFES). Advogada. http://lattes.cnpq.br/4649996800991390.
} 


\section{INTRODUÇÃO}

A sociedade brasileira na contextura presente conta com um Legislativo e Executivo que representa muito pouco da vontade popular aliada a uma pirâmide social demasiadamente injusta e uma Constituição com uma feixe aberto clamando para ser implementada. Assim, busca como cajado da sociedade o Poder Judiciário. Juízes são chamados a afirmar direitos que nem sempre são efetivados pelos poderes majoritários.

A coerência sobre o poder dos juízes não passa ilesa pelo exame de temas como legitimidade democrática, controle de constitucionalidade das leis, exercício da jurisdição constitucional contramajoritárias e teorias interpretativas para conceder maior objetividade as decisões judiciais. Entretanto, a experiência brasileira elevou o juiz como ator do processo democrático.

A partir da Constituição de 1988 o ofício do Poder Judiciário passou e continua passando por profunda transformação. Aliado as transformações desta instituição a sociedade brasileira busca, ainda que tardiamente, a concretização da democracia. Este é o perfil que os juízes encontram em sua atividade interpretativa: uma Constituição apta a concretizar direitos fundamentais, ferramentas jurídicas (controle difuso de constitucionalidade) e grupos minoritários débeis de direitos.

Sobre a necessidade de proteção social, um em cada quatro brasileiros que vive no campo está em situação de extrema pobreza. Segundo dado extraído do Censo Demográfico de 2010 a incidência da extrema pobreza no meio rural é de $25,5 \%$. E os índices não refrescam no que tange a agenda rural. Mais da metade da população rural tem até quatro anos de estudo e a taxa analfabetismo é de $20 \%$ enquanto 7,7\% no meio urbano. (BRASIL, 2013).

A proposta da Constituição de 1988 é garantir igualdade de acesso a direitos entre urbanos e rurais quanto à proteção aos riscos sociais. A contribuição dos benefícios previdenciários é, de fato, de grande valia na manutenção de renda da população idosa e tem contribuído para parcela da população se situe acima da linha da pobreza.

Assim, a expansão da política previdenciária, a partir de 1991, contribuiu para que uma grande massa de trabalhadores, sobretudo os rurais pudessem se aposentar com um benefício equivalente ao valor do salário mínimo. Os benefícios do setor representam um autêntico programa de renda mínima para os idosos residentes na área rural. 
Nesta agenda, nem sempre tais direitos são garantidos admnistrativamente. Assim, converge em maior litigiosidade gerando um empoderamento do Judiciário, também, em matéria previdenciária.

O presente estudo tem por objetivo salientar o empoderamento do Poder Judiciário nas questões afetas a Seguridade Social e se tal situação representa uma evolução da interpretação constitucional. Para tal, tem-se como escopo a àrea previdenciária que não passa incólume ao mesmo tempo ao discurso deficitário e ferramenta de implantação de efetiva democratização social no Brasil.

A relevância científica do estudo paira na hipótese de que as posturas do Judiciário (em políticas públicas ou atividade julgadora) em fins de seguridade social podem ser avisinhadas às discussões das teorias interpetativas constitucionais. No que tange ao enlevo social, o Poder Judiciário ao garantir direito à aposentação efetiva direito social agregando a grupos minoritários (segurados especiais) a ideia de progresso social ou seja, o alcance do desenvolvimento como um processo em que não haja mais lugar para limitação de capacidades individuais que impeçam o bem-estar dos seres humanos.

Como hipótese estuda-se atuação em políticas públicas do Judiciário, no chamado projeto Expedição da Cidadania e precedentes do Superior Tribunal de Justiça referente à proteção de direito social à aposentadoria do segurado especial nos Resp nº 1.352.721-SP (comprovação da atividade rural) e Resp n. ${ }^{\circ}$ 1649636/MT (tamanho da propriedade rural).

O trabalho inova ao trazer para o campo dos precedentes e ações políticas do Poder Judiciário em matéria previdenciária a discussão dos limites da atividade julgadora do juiz. Assim, o estudo reflete que o direito previdenciário também está dentro de um contexto de uma Constituição como resultado de um processo aberto, onde diversos intérpretes podem atuar na construção plural do texto podendo funcionar tanto como limite quanto incentivo ao poder criativo do juiz.

O referencial teórico pauta-se em um Judiciário que ao substituir políticas públicas do Poder Executivo e Legislativo (BAUM, 1987) na proteção dos riscos sociais o faz numa análise cautelosa da Constituição sem causar grandes rupturas (BARAK, 2002; ARAÚJO, 2017).

Como linha metodológica apresenta-se a weberiana, afastando-se das categorias sociológicas macroestruturais e utilizando-se o recurso do tipo ideal, para o compromisso explícito com a análise empírica do real. É de relevância ímpar que a realidade não possui um sentido intrínseco ou único, visto que são os indivíduos que lhe conferem significados. Assim, 
sítios eletrônicos do STJ, Associação dos Juízes Federais, Conselho Nacional de Justiça e revisão bibliográfica fazem parte do arcabouço metodológico.

O texto está dividido em três seções: a primeira traz reflexões sobre a dinâmica da proteção social em tempos de mundança no Brasil, sobretudo, uma breve análise da evolução da ideia protetiva alcançando os debates doutrinários da PEC n. ${ }^{\circ}$ 287/16. Na segunda, focará no empoderamento do Poder Judiciário no que tange à sua atividade julgadora e seus reflexos . Observa-se que projeto social e precedentes do Poder Judiciário mesmo que representem uma intensa atividade judicial substituindo políticas públicas de outros poderes apresenta um incrementalismo/evolucionismo constitucional em matéria previdenciária primando pela solidariedade social.

\section{A DINÂMICA DA PROTEÇÃO SOCIAL EM TEMPOS DE MUDANÇAS}

A inquietação com os infortúnios da vida é uma constante na humanidade. O homem tem se adaptado, desde os tempos antigos, no eixo de reduzir os feitos das adversidades da vida como doença, velhice. Ibrahim (2011) afirma que a verdadeira proteção social nasceu na família. Acontece que nem todas as pessoas eram dotadas de tal proteção familiar e mesmo quando existia era precária. Daí nasce a necessidade de auxílio externo, com natureza voluntária de terceiros, encabeçada pela igreja e mais tardiamente, o Estado, no século XVII, por meio da Lei dos Pobres.

Reduzida a mera caridade, naquele início, os infortúnios da vida aparece como algo desvinculado da ideia de justiça. A ajuda a pobres e necessitados era entendida após uma concepção de que a pobreza era vista como algo necessário, ou até mesmo um benefício para pessoas carentes, como efetiva garantia de inscrição no Reino de Deus. Ibrahim (2011, p. 01) fala que haveria uma honra inerente à pobreza. "[...] A indigência, não raramente, era apresentada como forma de punição divina, cabendo ao pobre arcar com todas as sequelas de sua condição, pois teria sido uma realidade gerada por sua própria culpa."

Ao decorrer da evolução da proteção social, o Estado passa a assumir, ainda que de forma tímida, parcela de responsabilidade pela assistência dos desprovidos de renda, até a criação de um sistema estatal coletivo, compulsório e securitário. Para Ibrahim (2011) os mecanismos de segurança social tem evoluído na medida que o próprio conceito de Estado 
modifica. Por exemplo, o conceito de Estado liberal tinha o discurso de intervenção mínima em áreas fundamentais, tais como segurança e atividade judicial. Nele, o governo era um mal necessário devendo dedicar-se ao estritamente necessário.

Daí o resultado de tal modelo foi o aumento das desigualdades existentes, onde aos mais carentes diminuíam as chances de atingir um nível de renda, sendo hostilizados pela tão sonhada iguadade de direitos. Assim, a necessidade de participação estatal, sobretudo, por meio de mecanismos legais, almejando uma correção ou minimização das desigualdades sociais. Pereira, Maravall e Przeworski (1993) chama atenção para a importância do Estado de aporte certo. Nele, deve-se adotar tendências mais intervencionaistas, ou seja, que atenda a outras demandas da sociedade, além das básicas, gerando igualdade de oportunidades como o ser humano no centro do desenvolvimento.

Tais embriões conceituais foram fomentadores da construção do chamado Welfare State, Estado de Bem-Estar Social, o qual visa atender outras demandas da sociedade, como o previdência. Contudo, Arretche (1995) faz uma análise da emergência e desenvolvimento do Welfare State por meio das diversas teorias explicativas. . O certo é qua a autora afirma que o fenômeno experimentou incontestável avolumamento inclusive institucionalização no período pós-guerra.

Arretche (1995) traça argumentos sobre os condicionantes de emergência e desenvolvimento do Welfare State como predominantemente de ordem econômica ou de ordem política. Para a autora, as produções teóricas acerca do tema no quesito econômico orbitam: a) como um desdobramento necessário as mudanças postas em marcha pela industrialização das sociedades; b) como uma resposta às necessidades de acumulação e legitimação do sistema capitalista. No quesito ordem política, o assunto se explica por meio de: a) um resultado de uma ampliação progressiva de direitos civis aos políticos, dos políticos aos sociais; b) resultado de um acordo entre capital e trabalho organizado, dentro do capitalismo; c) resultado de configurações históricas particulares de estruturas estatais e instituições políticas.

Após a intensa produção teórica detalhada por Arretche (1995, p. 35), conclui que ambos argumentos são campos de escolhas, de solução, de conflitos no interior de sociedades (capitalistas avançadas). Ajunta que são “[...]conflitos nos quais se decide a redistribuição dos frutos do trabalho social e o acesso da população à proteção contra riscos sociais inerentes à vida social, proteção concebida como direito de cidadania." 
No que tange ao Brasil, um esforço diria que as teorias aplicadas, quer seja no meio econômico ou político, ambas de uma forma mais ou menos intensa ocorreu no Welfare State brasileiro. Por exmplo, a Constituição de 1988 ampliou o rol dos direitos civis, políticos e sociais. Houve uma substituição do direito civil e o princípio da responsabilidade pelo direito social e o princípio da solidariedade como elementos reguladores da vida social.

Assim, o Brasil seguiu a mesma lógica ao prever um Estado de Bem-Estar Social em seu território. Cabe, ao Estado, prioritariamente, a obrigação de proteção social por pretações por meio de contribuições obrigatórias ou por mera necessidade. Logo, a Seguridade no Brasil rege-se pelo princípio da solidariedade, “[...] novo diagrama de regulação que estabelece que a responsabilidade (anteriormente individual) passa a ser social, dado que o fator de viver em sociedade representa um risco." (ARRETCHE, 1995, p. 22).

Acontece que o debate demonstrando que o Estado sozinho não seria capaz de efetivar tal solidariedade social demora a chegar no Brasil. Precisava de uma nova instituição para efetivá-los, o Poder Judiciário. O debate já era acalourado no retrato europeu e norte-americano, mas em terras brasileiras ocorreu no final dos anos 90, em que Leis como a 8.212/91 e 8.213/91 e o Regulamento n. ${ }^{o}$ 3.048/99. Tais instrumentos garantiam um início para a implementação de um direito principiológico e de uma constituição aberta, interpretada por todos os juízes e por toda comunidade jurídica, muito em voga em paragens brasileiras fruto da influência norteamericana.

A citada visão será ademais estudada e visualiza no modelo neoconstitucional. Entretanto, um intenso discurso deficitário tenta se encaixar na proposta de se interpretar a constituição como densificador de normas que pelo contexto aberto, comportariam inumeras possibilidades interpretativas. Ocorre que o Governo, fiel defensor do conceito de Bem-Estar Social já pulou do barco da solidariedade social por meio da PEC 287/16 (BRASIL, 2016a), agora, cabe refletir a visão das instituições do sistema de justiça sobre o tema.

Serau Jr. (2017, p. 92) não afirma para quem destina seu discurso, se aos juízes, Estado ou toda sociedade, mas convoca a necessidade de um movimento contrário de “[...] 'reconstitucionalização' das normas de Direito Previdenciário, quer dizer: certas matérias de Direito Previdenciário até então afetas a legislação ordinária passam a ser introduzidas no próprio Texto Constitucional”. 
Vista como um real descompasso com a realidade brasileira, Sarau Jr. (2017, p. 98) descreve que diversos pontos da PEC 287/2017 merecem acirradas críticas. Isto porque o autor focaliza os direitos sociais no campo de intensa interpretação constitucional em acordo com a expansão dos direitos fundamentais. Para o estudioso, seria a ocorrência de um "neoconstitucinalismo as avessas do Direito Previdenciário" e sua realização merece atenção no campo do Direito Internacional, visto que o Brasil estaria indo de encontro com compromissos asumido nos Tratados Internacionais de Direitos Humanos.

Já Galleti (2017, p. 99) sai do campo essencialmente da explicação na teoria do direito para conter a PEC n. 287/16. Para a autora, discursos de economia não pode sobrepor-se ao direito. A Constituição é soberana e como tal deverá ser cumprida. Mas quem será o gestor de tal caminhada em matéria previdenciária? Juízes ou Legisladores. O fato é que a pesquisadora não responde, mas afirma a importância da Previdência Social pois “[...] cumpre o papel central de proteger os cidadãos nas situações de vulnerabilidade. Negar-lhes esse papel e cuvar-se à lógica do dinheiro, é renegar a população à miséria e, mais, é lançar o país num círculo vicioso de assitencialismo."

Sobre a postura de Instituições de Justiça sobre o tema, a Associação dos Juízes Federais (AJUFE) colocou a PEC n. ${ }^{\circ}$ 287/16 dentro de sua agenda política institucional. Alertou que a referida proposta gerará intensas ações judiciais, sobretudo, nas regras de transição. Ademais, informou ao legislativo que os grandes causadores do déficit são os devedores e sonegadores, necessitando assim de um real aperfeiçoamento no sistema de arrecadação da Previdência. (AJUFE, 2017b). Seria o judiciário um braço político ou já adiantaria que não vai se isolar e que não vai deixar que poderes façam aquilo que lhes aprouver?

Não temos a tentativa de responder a pergunta, mas suscitar reflexões sobre o tema. $\mathrm{O}$ certo é que em artigo para a Revista de Previdência Social de outubro de 1991, Wagner Balera já falava em crise do sistema previdenciário brasileiro. A proposta à época era que um ouvidor para a Seguridade Social resolveria o problema de “[...] desmandos, escândalos, rombos e golpes, praticados a danos da seguridade social demonstram que, a máquina administrativa, torna-se cada vez mais lenta, cada vez mais ineficiente...”. (BALERA, 1991).

Parece que o artigo foi escrito hoje, mas não o foi. O que se coaduna com a atualidade é "[...] o apelo pela permanente valorização dos direitos do cidadão, mediante a institucionalização de vias confiáveis de comunicação entre povo e agentes políticos." (BALERA, 1991, p. 05). Desde modo, quem poderia resolver o problema hoje? Os juízes estão 
aptos para assumirem tal papel? Assim, o próximo tópico esforça-se para refletir sobre o crescimento do poder judicial e quais as ligações com as teorias interpretativas sobre os limites da atividade exegeta do juiz.

\section{O EMPODERAMENTO DO PODER JUDICIÁRIO E SEUS REFLEXOS}

Adjetivos como um mera "boca da lei" (bouche de la loi) ou legicentrista (légicentrisme) já não são mais aplicados aos juízes, dentro de um contexto de um sistema jurídico centralizado na lei ou no parlamento, em face da Constituição e do judiciário. Agora, não é mais o aplicador autômato da lei, mas, sobretudo, da Constituição vista de maneira aberta dentro de um arcabouço principiológico, possibilitando ao hermeneuta diversas possibilidades interpretativas.

O termo empoderamento (empowerment) no dicionário significa uma proposta coletiva desempenhada por alguns indivíduos que pertencem a grupos privilegiados de decisões. Tais grupos acrescem o desenvolvimento social, política ou econômica de indivíduos carentes das comunidades, a fim de alcançar mudanças positivas nas situações em que vivem. (MICHAELIS, 2017).

Um grupo privilegiado é o Poder Judiciário o qual tornou-se proeminente em matéria de julgar visto pelos doutrinadores americanos como um "ramo do governo" (branches of government) ou os juízes se transformam em verdadeiros legisladores. Ao imiscuirem-se em um contexto de desenvolvimento de indivíduos carentes funcionam como agente acriar do direito. Trata-se de um carater moderno do poder judicial que alcança um lugar de destaque na organização dos poderes estatais ao decidir sobre questões de alta complexidade política. (ARAÚJO, 2017).

Assim, tal empoderamento do Poder Judiciário tornou-se possível diante de um quadro construído a par de mudanças: do Estado de Direito para o Estado Constituional, do Positivismo para o Pós-Positivismo e a concretização do neoconstitucionalismo. Como consequência deste fazer política do judiciário surge a tona implicações, possivelmente a judicialização da política, o ativismo judicial e o conflito contramajoritário.

$\mathrm{Na}$ acepção de Zagrebelsky (1992), a forma de concepção histórica do Estado de Direito começou a se desenvolver na Inglaterra em fins do século XVII, na França e nos Estados 
Unidos, no final do século XVIII e na Alemanha e outros países europeus no século XIX. A proposta era conter o arbítrio estatal passando o poder a ser subordinado ao direito.

Acontece que a concentração da produção do direito era concentrada em apenas uma instância constitucional: a legislativa e não a judiciária. Logo, tudo o que está no direito seria o construído estritamente pela lei. Caberia ao jurista a simples exteriorização da vontade do legislador.

Ressalva Araújo (2017) que o referido Estado de Direito tornou-se perigoso ao possibilitar a legitimidade a qualquer Estado, sobretudo, autocráticos, mormente os que surgiram no século XX. Ademias, a II Guerra Mundial acabou por firmar tal preocupação emergindo a visão de um novo estado atento a criação de uma situação que permitisse ao ser humano o desenvolvimento de suas capacidades ocasionando modificações no entendimento dos direitos fundamentais e das técnicas jurídicas para a proteção de tal intento.

Nesse contexto cabe se falar em Estado Constitucional focado na oposição da visão positivista. Agora, o Direito se pauta na Constituição consusbtanciada numa análise essencialmente valorativa. A par desta compreensão, o Poder Judiciário passa a ser o garantidor da aplicação da Constituição.

Assim, no Estado Constitucional, a força normativa que a constituição passa a ter surgiu da necessidade de um instituição de poder para aplicá-la. “[...] o Poder Judiciário assume proeminência. Essa proeminência é o embrião da judicialização da política e pode ou não conduzir ao ativismo judicial, que daquela é dependente.” (ARAÚJO, 2017, p. 09).

Relembra Oliveira (2014) que o Positivismo Jurídico não coloca o aspecto humano como de grande importância na interpretação do direito, mas mantem elevada ênfase na lógica abstrativista e formalista. Com o fito de atribuir caráter científico ao direito, o positivismo concebe o direito como um feixe de regras válidas, as quais por si só exaurem seu conteúdo. Logo situações complexas que não estiverem expressamente percebidas na lei não poderiam ser resolvidas pelo direito.

Deste modo, como resolver situações sociais que buscam direitos que precedem a legislação? Como legitimar que minorias ou gurpos podem ter direitos em razão do julgamento do caso, mesmo que não sejam explicitamente reconhecidos por regras jurídicas? Situações que o Postitivismo Jurídico não pode resolver, mas um conceito de direito sobre os moldes argumentativos. 
Surgindo como uma ferramenta epsitemológica para o acolhimento de questões jurídico e constitucionais na contemporaneidade, o Pós-Positivismo se realiza como um fenômeno jurídico, um tanto complexo, pois cede lugar à decisão judicial em detrimento da lei. Agora o ordenamento jurídico como um todo é orientado " [...] por uma constituição forte e dotada de valores e princípios a serem efetivados na prática dos julgamentos e do exercício interpretativo cotidiano.” (ARAÚJO, 2017, p. 18).

Não se trata de uma visão transcendental do direito, nem posto por uma extrema cientificidade, mas um direito formulado dentro de um dever argumentativo com a valorização dos princípios constitucionais. Deste modo, frutifica as ideias neoconstitucionalistas almejando um hermeneuta voltado para a realidade unindo-se os vínculos entre Direito e Política, pois conceitos tão comuns em decisões judiciais (razoabilidade, senso comum e interesse público) são orientados por relações de poder. (ARAÚJO, 2017).

Diluição entre fronterias entre Legislativo e Executivo; maior independência, relevância do Poder Judiciário no que tange ao controle da administração e de algumas questões políticas em confronto com a constituição; desenvolvimento de novos meios de limitação efetiva do poder são indicados como consequências clássicas do neoconstitucionalismo (ARAÚJO, 2017; BARROSO, 2005, CAMBI, 2007). Mas o que se chama atenção é que este fenômeno tem fomentado uma expansão da jurisdição constitucional.

O Estado Constitucional, sobretudo, no Brasil, está em voga pela ocorrência do fenômeno da expansão da litigiosidade, em face da ampliação do acesso à Justiça. Como exemplo, tem-se para a agenda de análise de leis federais o chamado "Tribunal da Cidadania", o Superior Tribunal de Justiça, criado pela CF/88. Para tal Corte interesses de grupos minoritários (por exemplo, o trabalhador rural) deve ter soluções pautadas em princípios, não mais em reduzida nomartividade, mas com força de influir decisivamente em como analisar regras.

Na concepção neoconstitucionalista pode ser visto como intenso oleiro de direitos, por meio de uma acentuada excursão pela constituição. Atenta Araújo (2017) que o desenvolvimento da dogmática de interpretação judicial paira diante da compreensão e concretização de uma norma, as quais só serão realizadas diante de uma situação fática. Para ele, atribuir conteúdo à norma e sua aplicação ao caso concreto são um único processo. 
Mas como resolver o conflito contramajoritário como possível judicialização da política e ativismo judicial quando o juiz cria e modifica direito? O certo é que os indivíduos, assim como o próprio parlamento acabam acionando os juízes para resolver situações inóspitas que eles não podem ou não querem assumir o desgate de ressolver.

Espécie de Supremocracia (VIEIRA, 2008) ou Juristocracias (ARAÚJO, 2017)? O certo é que os defensores da expansão das cortes se abrigam em dois argumentos: a) a argumentação jurídica como ferramenta prática, mantendo uma argumentação racional e sobretudo, coerente; b) o isolamento político do poder judiciário, por meio de sua a partidarismo. (LANGFORD, 2015).

Neste contexto, o Poder Judiciário estaria na concatenação do espaco público e político criando uma nova relação constitucional entre estes dois meios, “[...] uma nova relação constitucional entre as duas 'sociedades' impondo o respeito aos direitos dos governados por parte dos órgãos do Estado”. (ARAÚJO, 2017, p. 30).

Embora o ativismo judicial seja tratado como uma expressão degastada e polissêmica ou como decisão incorreta (ARAÚJO, 2017), o certo é que no Brasil ainda é vista como uma das análise de KMIEC (2014) como atividade legislativa da Corte (legislative from the bench).

Contudo, importante é a análise do professor Shapiro (2013) que a própria atividade de controle de constitucionalidade, mesmo que vise tão somente a invalidação de uma lei acaba por legislar ou editar uma norma. Igualmente, o controle de constitucionalidade é um processo político, pois os juízes realizaram escolhas após as escolhas dos legisladores em um processo contínuo.

E a idéia do benefício da dúvida? Aquele em que os demais poderes devem reforçar as ações de outros poderes, exceto se houver violação clara à constituição? A referida concepção paira na hipótese de que não querem que o Poder Judiciário se interfira, mas ao contrário, que permita que os eleitos dentro de um processo democrático atuem como queiram. A abordagem majoritarista induz ao conflito majoritário das decisões judiciais.

Aponta Araújo (2017) que o Poder Legislativo no que tange à sua eleição e funcionamento pouco detém a pureza de ânsia popular. Nem todas as decisões que se baseiam numa análise constituicional-argumentativa dissoam da opinião pública. É verdade, o Poder Judiciário pode ser muito democrático, no enfoque de que sua decisão pode estar em submissão à opnião pública. Ademais, apresenta-se grande poder de aceitação que o Executivo é capaz de exercer sobre o Parlamento desnaturalizando a representatividade. 
Assim, é ínsito citar a teoria do grupos de interesses, ou seja, grupos representados pelo Poder Judiciário que não apresentam representação política eficaz no Parlamento (SHAPIRO, 2013). Dentro de tal grupo poderia elencar aqueles abarcados pelos riscos sociais na política previdenciária brasileira: o trabalhador rural. Populações que vivem em extrema pobreza no campo.

Ademais, em próximo tópico além da análise de precedente do STJ em possível política de enfrentamento à pobreza, numa postura pós-positivista e neoconstitucionalista se apresentará o Poder Judiciário em atividade política em uma análise constitucional antes da atividade decisória. Trata-se da crescente importância da atividade judicial em políticas públicas por meio do projeto "Expedição de Cidadania" o qual visa levar direitos e serviços essenciais a populações em situação de isolamento e pobreza em matéria previdenciária.

\section{A IMPORTÂNCIA DO JUDICIÁRIO EM MATÉRIA PREVIDENCIÁRIA: um} incrementalismo à brasileira

Segundo dados de 2015 da Justiça em Números produzido pelo CNJ, o Direito Previdenciário alcança as colocações de demandas na Justiça Federal de primeiro grau em $1^{\circ}$, $3^{\circ}, 5^{\circ}, 6^{\circ}, 10^{\circ}, 11^{\circ}, 12^{\circ}, 17^{\circ}, 19^{\circ}, 20^{\circ}$ colocações e em quase todas as posições no segundo grau e nas turmas recursais. (BRASIL, 2016). No mínimo os números demonstram uma intensa atuação dos juízes em matéria de proteção de riscos sociais.

Para alguns juristas, essa intensa atividade judicial pela incorporação de mecanismos juridicionais com o objetivo de promover a possibilidade de judicialização aos direitos fundamentais constitucionais atua como instância de apoio que facilita o acesso de grupos crescentes de cidadãos aos Tribunais (ARAÚJO, 2017). Para outros, os juízes, inclusive Tribunais de Segunda Instância, tentam maximizar seus poderes e, por isso, o poder de revisão (judicial review) pode, ao invés de dar garantias acabada atentando à democracia. (TUSHNET, 2013).

Parece que a atuação da Justiça Federal, como instituição do sistema de justiça, foi concebida para resolver disputas de forma que os litigantes não busquem as soluções privadas, inclusive a violência, com o fito de reivindicar seus direitos.

A atuação de Juízes Federais na sociedade brasileira vai muito além das suas atuações nos tribunais. “(...) Significa romper limites físicos dos Tribunais, foros, subseções para cumprir 
o seu ofício em localidades onde o acesso à justiça apresenta maiores dificuldades". Tal acertiva foi retirada da revista que trata da Política Institucional da Associação de Juízes Federais (AJUFE, 2017b, p. 106) e demonstra uma possível expansão do Poder Judiciário no domínio de políticas públicas outrora pertencentes exclusivamente para os poderes Executivo e Legislativo.

Assim, o projeto promovido pela Associação dos Juízes Federais do Brasil (Ajufe), intitulado de "Expedição de Cidadania", vem influenciando desde 2009 conjugando atuação em políticas públicas (atendimento jurídico, expedição de documentos, atendimentos médicos e odontológicos) com decisões judiciais em matéria previdenciária (benefícios e serviços). (AJUFE, 2017a).

Em verdade, trata-se de um projeto social do Poder Judiciário com parcerias (o Programa das Nações Unidas para o Desenvolvimento (PNUD), o Conselho Nacional de Justiça (CNJ), os Tribunais Regionais Federais da $1^{\mathrm{a}}$ e da $5^{\mathrm{a}}$ Regiões, o governo federal, o Ministério das Comunicações, o Instituto Nacional do Seguro Social (INSS), o Exército e a Marinha do Brasil) visando levar direitos e serviços essenciais a populações em situação de isolamento e pobreza. O projeto já alcançou populações ribeirinhas do Rio São Francisco e Paraguai, interior dos Estados da Bahia, Pernambuco, Mato Grosso e Mato Grosso do Sul e ocorrerá em trinta e um municípios do Maranhão.

A proposta da associação é institucionalizar o projeto tornando-o uma agenda nacional como parte do Judiciário Brasileiro e possa ter orçamento próprio para atender às ditas populações tradicionais do Brasil, como um braço político. Embora o projeto cite como diretriz a Política Nacional de Desenvolvimento Sustentável dos Povos e Comunidades Tradicionais (BRASIL, 2007) atende-se para o risco de politização do discurso no quesito jurisdição, pois a arena jurídica pode se transformar em um prolongamento do campo de duelo político, sem simbolizar vantagens para as discussões na seara política. (TAVARES, 2010).

Segundo o coordenador da Expedição, ocorrido em Paulo Afonso/BA, o judiciário seria uma mão visível fundamental que está atento ao contexto aberto da Constituição e que atua de acordo com a vontade do povo. Para o juiz federal João Paulo Pirôpo de Abreu, caso não ocorresse a expedição, muitas pessoas continuariam sem emitir seus documentos. “[...] Nós nos sentimos orgulhosos em facilitar a vida da população carente, ao mesmo tempo em que levamos dignidade e cidadania para cidadãos que necessitam de serviços sociais básicos". (AJUFE, 2017b). 
Percebe-se que o projeto em comento detalha um emponderamento do Poder Judiciário, em matéria previdenciária que nomalmente vai de mãos unidas com a proposta de interpretação argumentativa da constituição difusora de novos direitos fundamentais para um grupo excluído pelos demais poderes. (SHAPIRO, 2013). Ademais, reflete-se que tal postura judicial pode se fundar exatamente por ser um poder politicamente mais isolado e sem algum compromisso eleitoral e com as maiorias, assim, agi eficazmente na defesa da minoria.

Concebe-se que a atividade judicial nunca desempenhou um papel tão importante na política como hoje. Além do projeto citado, o STJ, vem enunciando um novo regime de normas previdenciárias, as quais repousam sobre uma concorrência permanente entre interpretações diferentes das regras constitucionais. Conclui que a escolha de um sentido não é jamais definitivo e que a interpretação deve evoluir, logo, novos direitos devem ser reconhecidos.

Nesta vertente, expõe-se os precedentes do STJ para a agenda rural no que tange a comprovação da atividade rural e extensão da propriedade rural para fins de configuração de segurado especial. Em ambos, a Corte federal posiciona a Seguridade Social dentro de um sistema de valores que se encontram nas leis e, sobretudo, na Constituição. Conjuntamente às regras estão os princípios dotados de alta normatividade.

No que tange à comprovação da atividade rural para fins de enquadramento como segurado especial, por exemplo, o artigo 39, I da Lei n. 8.213/91 exige como deferimento de benefícios o requisito comprovação laboral e idade (sessenta anos para homem e cinquenta e cinco anos para mulher). O problema enfrentado é como se comprovar essa atividade rural quer seja a nível administrativo, junto ao órgão gestor da Previdência ou, em caso de indeferimento administrativo, por meio de provimento judicial. Isto porque a informalidade e a pobreza no campo ainda são fatores que impede um planejamento destes trabalhadores em ter farta documentação em todo o período de labor rural.

Assim, no Resp no. 1.352.721-SP (BRASIL, 2016b) se decidiu que não há limitação de tempo da prova, muito menos um rol taxativo de documentos a ser demonstrados. Significa que o autor da ação previdenciária poderá posteriormente propor novo pedido de aposentação, caso reuna os documentos que comprovem sua atividade rurícula.

No referido julgado, o voto vencedor está recheiado de uma intensa interpretação argumentativa da correlação entre Constituição Federal e Lei Federal. Nele é ressaltado que devido as peculiaridades das demandas previdenciárias, é possível a flexibilização da rígida 
metodologia civilista. Ademais, "os cânones constitucionais atinentes à Seguridade Social, que tem como base o contexto social adverso em que se inserem os que buscam judicialmente os benefícios previdenciários”. (BRASIL, 2016b).

Ainda, demostrou-se que o próprio espírito da Seguridade Social é reparar distorções mediante situações sociais adiversas. Reafirmando que o caso de comprovação de atividade no campo, devido a informalidade da atividade e simplicidade do trabalhador, realiza-se num verdadeiro contexto de não paridade caso comparado com o aparato no qual o urbano detém.

No julgado, chama-se atenção para o espírito da Constituição Federal na defesa dos riscos sociais e o princípio da solidariedade social. Alerta à necessidade de proteção do trabalhador por meio da primazia da função social do RGPS, erguendo-se como direito fundamental de segunda geração o acesso à Previdência do Regime Geral. A par dessa lógica constitucional do seus valores morais, os pleitos previdenciários devem ser julgados no sentido de amparar a parte hipossuficiente culminando na flexibilização dos rígidos institutos processuais. (BRASIL, 2015).

Nesta mesma linha de atividade interpretativa ao pálio de argumentos constitucionais, no Resp n. ${ }^{\circ}$ 1649636/MT, o STJ também foi além do texto de Lei Federal e elencou um extenso rol de documentos segundo os quais o segurado especial pode atestar que de fato laborou no campo. Assim, os ditames do art. 106 da Lei 8.213/91 é exemplificativo, possibilitando outros documentos hábeis à comprovação do exercício de atividade. (BRASIL, 2017a).

Logo, certidões de casamento, de óbito, de nascimento dos filhos, Carteira de Trabalho e Previdência Social (CTPS), certificado de reservista, carteiras de beneficiário do extinto INAMPS, entre outros registros públicos contemplam a extensa interpretação judicial. (BRASIL, 2017a). Verifica-se uma interpretação jurídica da norma federal voltada para uma evolução da argumentação constitucional de efetividade de direitos fundamentais.

No que se refere a extensão da propriedade rural para fins de comprovação de segurado especial, no Agravo Interno no Recurso Especial n¹369260 / SC o STJ não se ateve extritamente frieza da legislação federal, mas decidiu a par de uma arrazoada aplicação de fatos considerados (regime de economia familiar escoltado no art. 195, $\S 8^{\circ}, \mathrm{CF} / 88$ ). (BRASIL, 2017b).

Assim, decidiu que o tamanho da propriedade não descaracteriza, por si só, o regime de economia familiar, desde que comprovados os demais requisitos para a concessão da aposentadoria por idade rural como ausência de empregados, mútua dependência e 
colaboração da família no campo. Percebe-se que o requisito "regime de economia familiar" não é uma regra constitucional, mas um princípio com alto teor valorativo. Logo, também se torna vetor de garantia de direitos fundamentais.

A par das decisões expostas o STJ não estaria acrescentando ou criando? Ou apenas aplica uma norma cujo significado é imposto e na verdade é tão somente porta-voz? Interpretações a parte ressalta-se que não se pode desconsiderar o inconveniente da concepção de que ao fazer o trabalho jurisdicional, aplicando uma norma constitucional, o Poder Judiciário deve, de alguma forma construir seu significado.

$\mathrm{Na}$ seara de grupos minoritários, como os segurados especiais ou populações em situação de vulnerabilidade contemplada pelo projeto Expedição da Cidadania o juiz se depara com a consagração judicial dos fugidios e difusos valores sociais. Informalidade, fome, pobreza, acesso à direitos básicos (saúde, educação, aposentadoria) entram em cena na concepção prévia do intérprete. O certo é que fizeram escolhas entre aplicações plausíveis ou entendimentos diferentes.

Observa-se no exposto que o judiciário, na proteção dos riscos sociais não optou por mudanças radicais de entendimento. Atuou de forma cautelosa em precedente que garante direitos sociais. A tal entendimento, Barak (2002) e Araújo (2017) chama de incrementalismo/interpretação evolutiva segundo a qual o juiz hermenêuta durante seu processo interpretativo constitucional não deve fazer rupturas, mas ao contrário, conduzir uma jurisprudência que deverá caminhar cautelosamente em uma dada direção.

O percurso seguido pela Corte Federal é a aposentadoria rural como direito social de segunda geração que deve ser efetivado, mesmo em um país de redemocratização tardia. São decisões prudentes, pois partem de uma lógica interpretativa da própria norma infraconstitucional, a qual deságua no contexto otimizador da Constituição Federal.

Ademais, a necessidade de mudar requer também a preocupação com a estabilidade. Na proposta do incrementalismo constitucional, a mudança deve ser por evolução e não por revolução. (BARAK, 2002). Percebe-se que o próprio texto constitucional espelhou a ideia de evolução por meio do princípio da solidariedade social, no artigo 195 da CF/88 demosntrando que além da conjuntura em que a norma foi editada deve se levar em consideração o fundamento racional que acompanha em sua vigência e o julgamento e interpretação que se fazem dela. 
Portanto, o incrementalismo e os precedentes citados estão juntos para garantir que o direito seguirá um caminho pausado de mudança, sobretudo, por um curso progressivo e revisões tênues do que por alterações de entendimentos bruscos e fundamentais. Não simboliza que a interpretação constitucional, em caso algum, poderá promover mudanças severas.

Em geral, reflete-se num papel salutar do constitucionalismo quando o judiciário tem a maestria de desenvolver princípios sobre uma gama de casos sem causar quebras. Entretanto, quando é apenas porta-voz de legislador indicando uma sucessão de regras vinculantes em um só tempo, perde a capacidade de ser um instrumento profícuo ao Estado Constitucional.

\section{CONSIDERAÇÕES FINAIS}

O esforço notado no estudo não teve o condão de propor uma intensa reflexão sobre hermenêutica constitucional, tão pouco criar uma metodologia em matéria de interpretação constitucional. A discussão até passou sobre a atividade criadora do juiz se legítima.

A proposta foi refletir sobre o empoderamento do poder judiciário em situações afetas à Seguridade Social, em sua área previdenciária e se suas atividades (políticas e jurídicas) estão alinhadas a um incrementalismo constitucional. As causas poderão se encontrar num contexto neoconstitucional ou até mesmo num neoconstitucionalismo às avessas. $\mathrm{O}$ certo é que, nos casos citados (projeto social e precedentes judiciais) existem uma proposta judicial de efetividade de direitos fundamentais na proteção de riscos sociais.

Agora, o judiciário tem consciência jurídica de como faz e o que faz em tempos de possível discurso deficitário? Os juízes estariam concentrando poderes demais? É possível um julgamento orientado pelo resultado em nome do progresso social e redução de pobreza no campo? Desde já se decidindo pela justiciabilidade, deve-se buscar a medida menos intrusiva possível em relação aos demais poderes, mas ainda consistente com a solução do problema.

Discutir o termo ativismo judicial, judicialização e autocontenção judicial para julgamentos do Supremo Tribunal Federal em casos de interrupção de gravidez dos afetos anencéfalos e uniões homoafetivas, por exemplo, ainda geram serevos debates sobre a polissemia e repercussões dos termos. Quiça alavancá-los para a seara das decisões previdenciárias. Apesar dos riscos, situações de extrema pobreza e a proposta de 
desenvolvimento social tão alinhados à Seguridade Social podem fazer com que juízes que atuem em varas, turmas previdenciária tenha uma interpretação criativa ao julgar.

Sabe-se que os grupos minoritários citados no estudo (agenda rural e populações em situação de vulnerabilidade) vivem em situação de extrema pobreza pulverizando a ideia de dignidade e desenvolvimento proposta pela Constituição. Ocorre que se deixarmos a cargo do Poder Judiciário como guardião dos Estado Constitucional, então o cumprimento de ambos os casos citados serão legítimos.

Deve-se debruçar perante a questão motivacional para revisão judicial em matéria previdenciária em vista das consequências sociais que as mesmas representam. Milhões de trabalhadores rurais serão alcançados pelos resultados das decisões. As referidas no estudo simbolizam uma evolução constitucional na vertente de reforço de direitos. Mas se a Corte se queda por uma interpretação restirtiva ou gramatical da Lei Federal Previdenciária?

A maior discussão na atualidade, em relação a atividade interpretativa do juíz é saber quais os limites dentro dos quais a atividade criadora do juiz é legítima. Dentre os limites colocados diante da exegese é atentar-se ao texto normativo e as regras de interpretação causando evolução e não revolução.

Talvez tal fórmula será importante para fins previdenciários, com a ideia de sistema protetivo. Contudo, poderá não ser para outras demandas. Assim, coadunou-se com a ideia de incrementalismo/evolucionismo constitucional como ferramenta de balizamento de decisão judicial. Segundo tal proposta, as posturas do Judiciário requerem também uma procupação com a estabilidade. Desta forma, o juiz mesmo autor de mudanças (políticas e jurídicas) deverá fazê-lo cautelosamente por meio de uma evolução constitucional.

O citado projeto social "Expedição da Cidadania" embora represente atuação jurídica em políticas públicas, não representa um conflito contramajoritário. Ao contrário, para seu desenvolvimento, encontra apoio dos demais poderes. Ademais ao resolver problemas sociais prementes o judiciário não exclui a esfera de atuação do Executivo ou Legislativo, mas sim agrega, incrementa. Não só os juízes farão políticas públicas no interior da Bahia ou Maranhão. Qualquer gestor público comprometido com a constituição poderá fazer.

A argumentação jurídica nos Resp no . 1.352.721-SP (comprovação da atividade rural) e Resp n. ${ }^{\circ}$ 1649636/MT (tamanho da propriedade rural) não propuseram mudanças radiciais de entendimento para o campo previdenciário. A jurisprudência do STJ já vinha caminhado 
cautelosamente em uma mesma direção: constitucionalização da Seguridade Social, que tem como base o contexto social adverso em que se inserem os que buscam judicialmente os benefícios previdenciários.

Observa-se que o projeto social Expedição da Cidadania e precedentes do Superior Tribunal de Justiça para o segurado especial são propostas de incremento da Constituição Federal. Mesmo que representem uma intensa atividade judicial substituinado políticas públicas de outros poderes apresenta uma evolucionismo constitucional em matéria previdenciária primando pela solidariedade social.

Ademais, representa aperfeiçoamento, pois alerta à necessidade de proteção do trabalhador por meio da primazia à função social do RGPS, erguendo-se como direito fundamental de segunda geração o acesso à Previdência do Regime Geral. Portanto, o juíz interprete não causou revolução, mas evolução constitucional.

\section{REFERÊNCIAS}

ARAÚJO, Luiz Henrique Diniz. O ativismo judicial e seus limites. Belo Horizonte: Arraes Editores, 2017.

ARRETCHE, Marta T. S. Emergência e Desenvolvimento do Welfare State: Teorias explicativas. Boletim Informativo e Bibliográfico de Ciências Sociais-BIB, Rio de Janeiro, n. ${ }^{\circ} 39,1^{\circ}$ semestre 199. p. 03-40.

\section{ASSOCIAÇÃO DOS JUÍZES FEDERAIS- AJUFE. Ações da Ajufe. Expedição da}

Cidadania. Disponível em: www.ajufe.org/acoes-da-ajufe/expedicao-da-cidadania. Acesso em 08 ago 2017.

Expedição da cidadania. Agenda político-institucional Ajufe 2017, $1^{\circ}$ ed, Brasília, 2017. p. 121.

BALERA, Wagner. Um ouvidor para a Seguridade Social. Revista de Previdência Social. Ano 15, n. ${ }^{\circ} 131$, outubro, 1991, LTr editora, São Paulo.

BARROSO, Luís Roberto. Neoconstitucionalismo e constitucionalização do Direito $9^{\circ}$ triunfo tardio do Direito Constitucional no Brasil). In: Revista Brasileira de Direito Público -

RBDP, n. 11, out/dez. 2005, Editora Forum, Rio de Janeiro.

BRASIL. Duas décadas de desigualdade e pobreza no Brasil medidas pela Pnad/IBGE.Instituto de Pesquisa Econômica Aplicada- IPEA. Brasília, DF: IPEA, 2013. (Comunicados do IPEA, n. 159). 
Decreto n. ${ }^{\circ} 6040$ de 07 de fevereiro de 2007. Institui a Política Nacional de Desenvolvimento Sustentável dos Povos e Comunidades Tradicionais. Diário Oficial da União - Seção 1 - 8/2/2007, Página 316 . Disponível em: http://www.planalto.gov.br/ccivil_03/_ato2007-2010/2007/decreto/d6040.htm. Acesso em: 08 ago 2017.

. Justiça em números 2016: ano-base 2015. Conselho Nacional de Justiça - Brasília: CNJ, 2016, p. 404.

.Lei $\mathrm{n}^{\circ}$ 8.213, de 24 de julho de 1991. Dispõe sobre os Planos de Benefícios da Previdência Social e dá outras providências. Diário Oficial [da] República Federativa do Brasil, Poder Executivo, Brasília, DF, Seção 1 de 25 de jul. de 1991, Página 14809.

Disponível em: http://www.planalto.gov.br/ccivil_03/leis/18213cons.htm. Acesso em: 29 ago. 2015.

Proposta de Emenda Constitucional n..$^{\circ}$ 287/16. Altera os arts. 37, 40, 109, 149, 167, 195, 201 e 203 da Constituição, para dispor sobre a seguridade social, estabelece regras de transição e dá outras providências. Disponível em: http://www.camara.gov.br/proposicoesWeb/prop_mostrarintegra;jsessionid=E964952D49FC AE59F6835FD875873846. proposicoesWebExterno2? codteor $=1514975 \&$ filename $=\mathrm{PEC}+287 /$ 2016. Acesso em 08 ago 2017.

Superior Tribunal de Justiça. Recurso Especial n ${ }^{\circ}$ 1.352.721-SP, Rel. Min. Napoleão Nunes Maia Filho, Corte Especial, julgado em 16/12/2015. Diário de Justiça de 28/4/2016b. Disponível em:

http://www.stj.jus.br/SCON/jurisprudencia/doc.jsp?livre=TRABALHADOR+RURAL\&repeti tivos=REPETITIVOS\&b=ACOR\&p=true $\& l=10 \& \mathrm{i}=1$. Acesso em: 17 mar 2017.

Superior Tribunal de Justiça. Recurso Especial n 1649636 / MT, Rel. Min. Herman Benjamin, Segunda Turma, julgado em 28/03/2017.

Diário de Justiça de 19/04/2017a. Disponível em:

http://www.stj.jus.br/SCON/jurisprudencia/doc.jsp?preConsultaPP=000004946/0\&b=ACOR $\& \mathrm{p}=$ true $\& \mathrm{t}=\mathrm{JURIDICO} \& \mathrm{l}=10 \& \mathrm{i}=2$. Acesso em: 08 ago 2017.

Superior Tribunal de Justiça. Agravo interno no Recurso Especial n ${ }^{\circ} 1369260$ / SC. Rel. Min. Napoleão Nunes Maia Filho, Primeira Turma, julgado em 13/06/2017. Diário de Justiça de 26/06/2017b. Disponível em:

http://www.stj.jus.br/SCON/jurisprudencia/doc.jsp?preConsultaPP=000004946/0\&b=ACOR

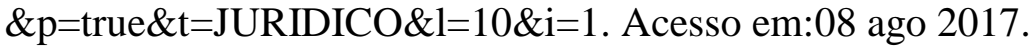

CAMBI, Eduardo. Neoconstitucionalismo e Neoprocessualismo. Panóptica, ano 1, n. 6.pp. 144, Vitória-ES, 2007. 
GALLETI, Tonia Andrea Inocentini. A reforma da previdência e a defesa da Constituição de 05 de outubro de 1988. Juris Plenum Previdenciária. Ano V, n. ${ }^{\circ}$ 17, fevereiro, Editora Plenum, Caxias do Sul, 2017.

IBRAHIM, Fábio Zambitte. Curso de Direito Previdenciário. 12 ed. Rio de Janeiro. Impetus, 2011.

LANGFORD, Malcolm. Why Judicial Review. In: Oslo Law Review, 2015, Issue 1, p. 3685. Disponível em: https://www.idunn.no/oslo_law_review/2015/01/why_judicial_review. Aceso em 08 ago 2017.

KMIEC, Keenan D. The Origin and Current Meaning of "Judicial Activism". California Law Review, v. 92, n. 5. 2004, p. 1441-1477.

MICHAELIS. Dicionário Brasileiro da Língua Portuguesa. São Paulo: Editora Melhoramentos, 2017. Disponível em:

http://michaelis.uol.com.br/busca? $\mathrm{r}=0 \& \mathrm{f}=0 \& \mathrm{t}=0 \&$ palavra=empoderamento. Acesso em: 07 ago 2017.

OLIVEIRA, Rafael Tomaz. Expressão Pós- Positivismo necessita passar por uma limpesa semântica. Consultor Jurídico. Disponível em: http://www.conjur.com.br/2014-ago09/diario-classe-expressao-pos-positivismo-necessita-passar-limpeza-semantica. Acesso em 08 ago 2017.

PEREIRA, Luis Carlos; MARAVALL, José Maria; PRZEWORSKI, Adam. Reformas Econômicas em Democracias Novas. São Paulo: Nobel, 1993.

SERAU JR., Marco Aurélio. Reforma da Previdência (PEC 287/2016) e a Neoconstitucinalização (às avessas) do Direito Previdenciário. Juris Plenum Previdenciária. Ano V, n. ${ }^{\circ}$ 17, fevereiro, Editora Plenum, Caxias do Sul, 2017.

SHAPIRO, Martin. Judicial Independence: New Challenges in Establish Nations. In: Indiana Journal of Global Legal Studies, n. 20. 2013. p. 255.

TAVARES, André Ramos, Minorias e Justiça Constitucional. In: Revista Brasileira de Estudos Constitucionais- RBEC, ano 4, n. ${ }^{\text {o }}$ 13, jan/mar 2010, Belo Horizonte, p. 11-30.

VIEIRA, Oscar Vilhena. Supremocracia. Revista de Direito FGV, São Paulo, jul-dez 2008. p. 441-464.

ZAGREBELSKY, Gustavo. Il diritto mite. Einaudi. Torino, 1992. 